\title{
Stroke prevention and control in Brazil: missed opportunities
}

\author{
Prevenção e controle do AVC no Brasil: oportunidades perdidas \\ Jefferson Gomes Fernandes
}

Faculdade de Educação e Ciências da Saúde, Hospital Alemão Oswaldo Cruz, Sao Paulo SP, Brazil.

Correspondence: Jefferson Gomes Fernandes; Faculdade de Educação e Ciências da Saúde, HAOC; Rua João Julião, $245-1^{\circ}$ andar; 01323-903, São Paulo SP, Brasil; E-mail: jeffersonfernandes@haoc.com.br Conflict of Interest:

There is no conflict of interest to declare.

Received 31 July 2015; Accepted 07 August 2015

\section{(c) BY-NC}

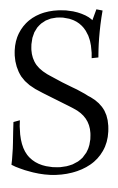

everal studies have shown that stroke has a huge global impact with a considerable financial cost both to health and care services and to patients and their families. Stroke is one of the leading causes of mortality and disability in Latin America and the Caribbean ${ }^{1}$. Brazil presents the fourth worst stroke mortality rate among these countries with an early in-hospital stroke mortality rate of $34.3 \%$ which is high when compared to the rates in Canada (6.9\%) or the Netherlands $(17.3 \%)^{2}$. Stroke mortality varies considerably according to social and economic development and about $85 \%$ of strokes occur in low- and middle-income countries (LMIC) with one third affecting the economically active population $^{3.4}$. A recent publication from the Global Burden of Disease Collaborators has shown that stroke is among the three main causes of years of life lost in Brazil ${ }^{5}$. The demographic transition occurring in most developing countries towards an increase of the older population will amplify the impact of stroke.

Understanding the epidemiology and risk factors for stroke is important to be able to identify people at risk and implement preventative interventions. Hypertension is probably the most important and well-documented risk factor ${ }^{6}$ and there is overwhelming evidence that its control reduces the absolute and relative risk of stroke ${ }^{7,8}$.

Population-based surveys are crucial for quantifying the disease burden, contributing to evidence-based healthcare planning, and evaluating the effectiveness and relative contribution of various primary and secondary/tertiary preventative measures for reducing the burden of diseases such as stroke9.

In this issue of Arquivos de Neuropsiquiatria, Bensenor et al. ${ }^{10}$ publish an important study which assesses the self-declared prevalence of stroke in the Brazilian population using the National Health Survey (Pesquisa Nacional de Saúde - PNS) undertaken in 2013 that covered both urban and rural areas and included information on gender, race/self-reported skin color, education level and occupation. This study estimated that there were 2.231.000 people who had suffered a stroke and 568.000 stroke cases with severe disabilities and showed high stroke prevalence rates especially in older individuals without formal education and urban dwellers. The findings of this survey reveal the scale of the challenges in terms of stroke prevention and control in Brazil.

Primary care offers the best opportunity for preventive interventions in people at risk of stroke. Evidence-based guidelines ${ }^{11}$ for primary stroke prevention are easily available in many countries. Despite this, patients who present at hospital with first stroke have been found to have multiple untreated or undertreated risk factors ${ }^{12}$ illustrating missed opportunities. Studies of the use and adherence to stroke prevention guidelines are few and limited.

Cost-effective interventions are available for secondary prevention of stroke, and the potential gains associated with the consistent use of such interventions are very large. Making these interventions accessible to all patients with stroke could lead to substantial individual and public health benefits.

Phase 1 of the WHO-PREMISE study ${ }^{13}$ is aimed at assessing current practice patterns related to secondary prevention of cardio and cerebrovascular disease (CVD) and identifying barriers and opportunities for scaling up secondary prevention. It was conducted in areas of ten LMIC including Brazil (Porto Alegre). This study showed that several measures of well established secondary prevention interventions were far behind what would 
be expected, indicating significant gaps in stroke care and prevention. For instance, the use of aspirin varied among these countries from $30.9 \%$ to $90.1 \%$ among stroke patients, being $58.8 \%$ in Brazil.

An international workshop on secondary prevention of CVD in $\mathrm{LMIC}^{14}$ identified that we are doing well in conducting trials to establish the efficacy of treatments, in the application of health economics to get cost-effective interventions and in the ability to synthesise evidence to produce guidelines. However, we are doing badly due to delays and an inability to implement what is known (cost-effective prevention), causing suffering (morbidity), loss of many lives (mortality) and financial loss. In addition, there has been insufficient investment in evaluating the effects of populational and non-pharmacological interventions, health services for people with CVD are poorly organized and there is a lack of trained health professionals (for health system management and health promotion, prevention and control).

Health systems capacities need to be enhanced through the development and implementation of proactive policies at municipal, state and federal levels in Brazil. It was only in 2012 that the Brazilian Ministry of Health produced and published important policies for the public national health system (SUS) for people with stroke, the so called Line of Care for People with Stroke (Linha de Cuidados para as Pessoas com Acidente Vascular Cerebral ${ }^{15,16}$ which included contributions from neurologists as specialist consultants (JG Fernandes, RV Sant'Anna and SCO Martins). Among the aims of these policies is the reduction of the impact of cerebrovascular diseases in Brazil through continuous integrated patient care in all of his/ her health needs. This "Line of Care" policy includes proposals to make improvements in: health education for the population, primary care actions, pre-hospital and hospital emergency care, stroke units, implementation of evidence-based protocols, rehabilitation, out-patient care and social reintegration. Public health authorities at different levels, health organizations and institutions, health professionals and others should work together towards the implementation of such policies to reduce the burden of stroke in Brazil.

Lessons can be learned from developed countries initiatives for stroke care and prevention ${ }^{17}$. The use of telemedicine for stroke care has abundant evidence in the literature regarding its safety, efficacy and cost-effectiveness ${ }^{18,19}$. A telestroke project in Brazil for emergency departments of public hospitals around the country has started to show its benefits by reducing hospital mortality and stay of stroke patients and also by increasing the percentage of thrombolysis in eligible patients ${ }^{20}$.

Using the evidence base, it is possible to demonstrate both the opportunities that exist for preventing strokes and the potential of these opportunities to do more in terms of saving lives, preventing disability, releasing healthcare resources, reducing inequalities and avoiding missed opportunities.

\section{References}

1. Lavados PM, Hennis AJ, Fernandes JG, Medina MT, Legetic B, Hoppe A et al. Stroke epidemiology, prevention, and management strategies at a regional level: Latin America and the Caribbean. Lancet Neurol. 2007;6(4):362-72. doi:10.1016/S1474-4422(07)70003-0

2. Rolim CL, Martins M. Qualidade do cuidado ao acidente vascular cerebral isquêmico no SUS. Cad Saúde Pública. 2001;27(11): 2106-16. doi:10.1590/S0102-311X2011001100004

3. World Health Organization. Stepwise approach to stroke surveillance. Overview and Manual (version2.0). Noncommunicable Diseases and Mental Health. Geneva: World Health Organization; 2015 [cited 2015 July 30]. Available from: http://www.who.int/entity/ ncd_surveilance/steps/en

4. Yach D, Hawkes C, Gould CL, Hofman KJ. The global burden of chronic diseases: Overcoming impediments to prevention and control. JAMA. 2004;291(21):2616-22. doi:10.1001/jama.291.21.2616

5. GBD 2013 Mortality and Causes of Death Collaborators. Global, regional, and national age-sex specific all-cause and cause-specific mortality for 240 causes of death, 1990-2013: a systematic analysis for the Global Burden of Disease. Lancet. 2015;385(9963):117-71. doi:10.1016/S0140-6736(14)61682-2

6. Lewington S, Clarke R, Qizilbash N, Peto R, Collins R. Age-specific relevance of usual blood pressure to vascular mortality: a meta-analysis of individual data for one million adults in 61 prospective studies. Lancet. 2002;360(9349):1903-13. doi:10.1016/S0140-6736(02)11911-8

7. Gaciong Z, Siński M, Lewandowski J. Blood pressure control and primary prevention of stroke: summary of the recent clinical trial data and meta-analyses. Curr Hypertens Rep. 2013;15(6):559-74. doi:10.1007/s11906-013-0401-0
8. Lakhan SE, Sapko MT. Blood pressure lowering treatment for preventing stroke recurrence: a systematic review and meta-analysis. Int Arch Med. 2009;2(1):30. doi:10.1186/1755-7682-2-30

9. Feigin VL, Howard G. The importance of epidemiological studies should not be downplayed. Stroke. 2008;39(1):1-2. doi:10.1161/STROKEAHA.107.503250

10. Benseñor IM, Goulart AC, Szwarcwald CL, Vieira MLFP, Malta,SC, Lotufo PA. Prevalence of stroke and associated disability in Brazil: National Health Survey - 2013. Arq Neuropsiquiatr 2015;73(9):746-50. doi: 10.1590/0004-282X20150115

11. Guidelines for the Primary Prevention of Stroke. A Statement for healthcare professionals from the American Heart Association/American Stroke Association. Stroke. 2014;45(1):1-79.

12. Guptha SH, Shibu P, Owusu-Agyei P. Stroke prevention: missed opportunities. Lancet. 2007;369(9565):904-5. doi:10.1016/S0140-6736(07)60444-9

13. Mendis S, Abegunde D, Yusuf S, Ebrahim S, Shaper G, Ghannem H et al. WHO study on Prevention of REcurrences of Myocardial Infarction and StrokE (WHO-PREMISE). Bull World Health Organ. 2005;83(11):820-9.

14. World Health Organization. Secondary prevention of noncommunicable diseases in low -and middle-income countries through communitybased \& health service interventions. Report of WHO-Wellcome Trust Meetinf of Experts, 2001 Aug. 1-3, Hinxton, Cambridge. Geneva: World Health Organization; 2007 [cited 2015 July 30]. Available from: http:// www.who.int/cardiovascular_diseases/media/en/615.pdf

15. Ministério da Saúde (BR). Portaria No 664, de 12 de abril de 2012. Aprova o Protocolo Clínico e Diretrizes Terapêuticas - Trombólise no Acidente Vascular Cerebral Isquêmico Agudo. Diário Oficial União. 13 abr 2012;seção 1:33 
16. Ministério da Saúde (BR). Portaria No 665, de 12 de abril de 2012. Dispõe sobre os critérios de habilitação dos estabelecimentos hospitalares como Centro de Atendimento de Urgência aos Pacientes com Acidente Vascular Cerebral (AVC), noâmbito do Sistema Único de Saúde (SUS),institui o respectivo incentivo financeiro e aprova a Linha de Cuidados em AVC. Diário Oficial União. 13 abr 2012

17. Centers for Disease Control and Prevention. Paul Coverdell National Acute Stroke Registry Program Summary Report, 2007-2012. Atlanta: US Dept of Health and Human Services; 2015.

18. Hubert GJ, Müller-Barna P, Audebert HJ. Recent advances in TeleStroke: a systematic review on applications in prehospital management and Stroke Unit treatment or TeleStroke networking in developing countries. Int J Stroke. 2014;9(8):968-73. doi:10.1111/ijs.12394

19. Switzer JA, Demaerschalk BM, Xie J, Fan L, Villa KF, Wu EQ. Cost-effectiveness of hub-and-spoke telestroke networks for the management of acute ischemic stroke from the hospitals' perspectives. Circ Cardiovasc Qual Outcomes. 2013;6(1):18-26. doi:10.1161/CIRCOUTCOMES.112.967125

20. Barbosa IA, Silva KC, Piza PVT, Oliveira RMC, Fernandes JG. Impact of telestroke implementation in a Brazilian public hospital. Int J Stroke. 2014;9(suppl 3):294. 